\title{
Beta Relaxations in Semicrystalline Poly(aryl ether ether ketone) Films. Mechanical Coupling and Interactions between Phases
}

\author{
Corine Bas and N. Dominique Albérola ${ }^{\dagger}$ \\ Laboratoire Matériaux Polymères et Composites-Université de Savoie, Campus Scientifique, \\ Bâtiment IUT, 73376 Le Bourget-du-Lac Cedex, France
}

(Received September 26, 1996)

\begin{abstract}
Mechanical spectrometry was performed on poly(aryl ether ether ketone) (PEEK) polymer films in order to evaluate the influence of a crystalline phase on the beta-relaxation. The Halpin-Kardos model has been applied to describe the beta dynamic mechanical behavior of semicrystalline PEEK films considered as composite materials. Changes in the low-temperature component of the beta-relaxation induced by the crystalline phase are discussed in terms of mechanical coupling between phases. Moreover, it is found that the pattern of the higher temperature component of the beta transition is governed, in addition, by the rigid amorphous phase.

KEY WORDS Semicrystalline poly(aryl ether ether ketone) / Dynamic Mechanical Behavior / Beta Relaxation / Halpin-Kardos Model / Mechanical Coupling / Rigid Amorphous Phase /
\end{abstract}

Poly(aryl ether ether ketone) (PEEK) is an aromatic engineering themoplastic polymer displaying excellent mechanical properties and good thermal stability. A lot of papers deal with the mechanical behavior of amorphous and semicrystalline PEEK. Some work has attempted to establish the relationships between the microstructure and the mechanical properties of amorphous and semicrystalline PEEK. ${ }^{1-3}$ Conversely, the microstructure of PEEK can be illuminated by a study of their mechanical or dielectric relaxation. Moreover, from previous work carried out on other polymers (polystyrene, epoxy, and bisphenol A polycarbonate), it was shown that subglass transitions may govern the mechanical behavior of polymers. ${ }^{4-9}$

The dynamic mechanical properties of PEEK below the glass transition have been studied by many authors. But, mechanical and dielectric spectra displayed by PEEK at low temperature are complex and have been considered as resulting from the superimposition of various components:

(i) According to Ahlborn ${ }^{10}$ and Jonas and Legras, ${ }^{11}$ a $\gamma$-relaxation is observed at about $-155^{\circ} \mathrm{C}$ at $7 \mathrm{~Hz}$.

(ii) At higher temperatures, in the -100 to $+100^{\circ} \mathrm{C}$ temperature range, a broad $\beta$-relaxation spectrum is observed. There is also some controversy concerning the molecular origin of the various relaxations which can occur in this temperature range. ${ }^{11-15}$ The influence of the crystalline phase on the $\beta$ spectrum has been studied by some authors. They conclude to a decrease in the mechanical $\beta$ spectrum magnitude only due to interactions between amorphous and crystalline phases. Nevertheless, the respective contribution of mechanical coupling effect and interactions between phases on the pattern of the $\beta$ spectrum was not discussed in such work. ${ }^{11-14}$

As a matter of fact, according to Albérola, ${ }^{16,17}$ changes in viscoelastic spectra for composites (and semicrystalline polymers) near $T_{\mathrm{g}}$ could be related to the two following causes: (i) the mechanical coupling effect

\footnotetext{
† To whom correspondence should be addressed.
}

between polymer matrix (amorphous phase) and the inclusions and (ii) the reducion of chain mobility because the presence of additional interactions between phases.

In this paper, it is proposed to separate the respective contribution of these two causes on the mechanical behavior of semicrystalline PEEK films over the $-150^{\circ} \mathrm{C}$ to $+100^{\circ} \mathrm{C}$ temperature range which can be performed through a mechanical model.

\section{EXPERIMENTAL}

\section{Sample Preparation}

Poly(aryl ether ether ketone) (PEEK) (trademark: stabar K200 "Victrex") samples were supplied by I.C.I. films Company (U.K.) as amorphous sheets of about $250 \mu \mathrm{m}$ thickness.

Samples were dried by heating the as-received films at $145^{\circ} \mathrm{C}$ under high vacuum during six hours. Then, to erase the previous thermal history and to give a similar isoconfigurational state, samples were heated for 10 minutes at a temperature higher than the glass temperature $\left(150^{\circ} \mathrm{C}\right)$ and then quenched to room temperature in air. FTIR and WAXS analyses performed on such samples show that such thermal treatments do not induce crystallization and constitute an effective drying procedure. ${ }^{15}$

The dry and freshly quenched films were isothermally crystallized from the amorphous state for different keeping times and temperature conditions. Table I gives the nomenclature and processing conditions of the investigated samples.

\section{Degree of Crystallinity Determinations}

Density $(\rho)$ was evaluated using a top-loading electronic Mettler balance according to the Archimedean principle and by weighing samples in air and in ethanol. Volume crystallinity index, $X_{\mathrm{cv}}$, was then determined from the specific weight of a pure amorphous phase $\left(\rho_{\mathrm{a}}=1.236 \mathrm{~g} \mathrm{~cm}^{-3}\right)^{18}$ and of the crystal phase $\left(\rho_{\mathrm{c}}=1.4 \mathrm{~g}\right.$ $\left.\mathrm{cm}^{-3}\right) .{ }^{19}$ 
Table I. Nomenclature, annealing conditions, and crystallinity degree

\begin{tabular}{|c|c|c|}
\hline $\begin{array}{l}\text { Sample } \\
\text { name }\end{array}$ & Thermal treatment & $\begin{array}{l}\text { Crystallinity } \\
\text { index } / X_{\mathrm{cm}}\end{array}$ \\
\hline A & Dry and freshly quenched sample & 0 \\
\hline A160 & $\begin{array}{l}\text { Sample } \mathrm{A}+\text { annealing for } 30 \mathrm{~min} \text { at } 160^{\circ} \mathrm{C} \\
\text { then quenched }\end{array}$ & 0.17 \\
\hline A200 & $\begin{array}{l}\text { Sample } \mathrm{A}+\text { annealing for one hour at } 200^{\circ} \mathrm{C} \\
\text { then quenched }\end{array}$ & 0.24 \\
\hline A250 & $\begin{array}{l}\text { Sample } \mathrm{A} 200+\text { annealing for one hour at } \\
250^{\circ} \mathrm{C} \text { then quenched }\end{array}$ & 0.28 \\
\hline A 320 & $\begin{array}{l}\text { Sample } \mathrm{A}+\text { annealing for } 30 \mathrm{~min} \text { at } 320^{\circ} \mathrm{C} \\
\text { then quenched }\end{array}$ & 0.32 \\
\hline
\end{tabular}

The wide-angle X-ray diffractograms of the as-received and annealed samples were recorded at room temperature by using a INEL CPS 120 diffractometer (Co- $K_{\alpha 1}$ filtered radiation) with $0.02^{\circ}(2 \theta)$ scan increments. The degree of crystallinity $\left(X_{\mathrm{cm}}\right)$ was obrained from the area of crystalline $X$-ray diffraction peaks after subtracting the contribution of the amorphous phase. The crystallinity indexes are reported in Table I.

\section{Differential Scanning Calorimetry (DSC) Experiments}

Differential scanning calorimetry (DSC) experiments were carried out from $+50^{\circ} \mathrm{C}$ to $+400^{\circ} \mathrm{C}$ with a Perkin Elmer DSC-7 instrument purged with nitrogen gas. DSC traces were recorded at a heating rate of $100^{\circ} \mathrm{Cmin}^{-1}$ in order to limit a possible structural reorganisation on heating. ${ }^{20,21}$ Thermograms were calibrated by scanning reference substances (indium and zinc) at the same heating rate.

Glass transition is detected by the endothermic change in the slope of the curve. The glass transition temperature is chosen to be the temperature corresponding to the half specific heat jump $\left(\Delta C_{\mathrm{p}}\right)$.

\section{Dynamic Mechanical Analysis}

Dynamic mechanical experiments have been carried out in tensile mode with a dynamic mechanical thermal analyser MKII Polymer Laboratories. A dynamic deformation of $16 \mu \mathrm{m}$ was superimposed on a static deformation equal to twice the amplitude of the dynamic deformation. Isochronal scans from $1 \mathrm{~Hz}$ to $10 \mathrm{~Hz}$ were recorded from $-150^{\circ} \mathrm{C}$ to $+100^{\circ} \mathrm{C}$ at a heating rate of $0.5^{\circ} \mathrm{C} \cdot \mathrm{min}^{-1}$

\section{RESULTS AND DISCUSSION}

\section{Sample Characterizations}

The DSC traces displayed by PEEK samples isothermally crystallized are shown in Figure 1. The arrows indicate the annealing temperature. Excepted for the A320 sample, two melting peaks at about $20^{\circ} \mathrm{C}$ higher than the annealing temperature can be distinguished. The higher temperature endotherm is at $334^{\circ} \mathrm{C}$. The A320 PEEK sample only displays one endothermic peak at this temperature.

Moreover, all samples show a specific heat jump related to the glass transition which characteristics are reported in Table II.

According to the literature, ${ }^{1,22,23}$ semicrystalline

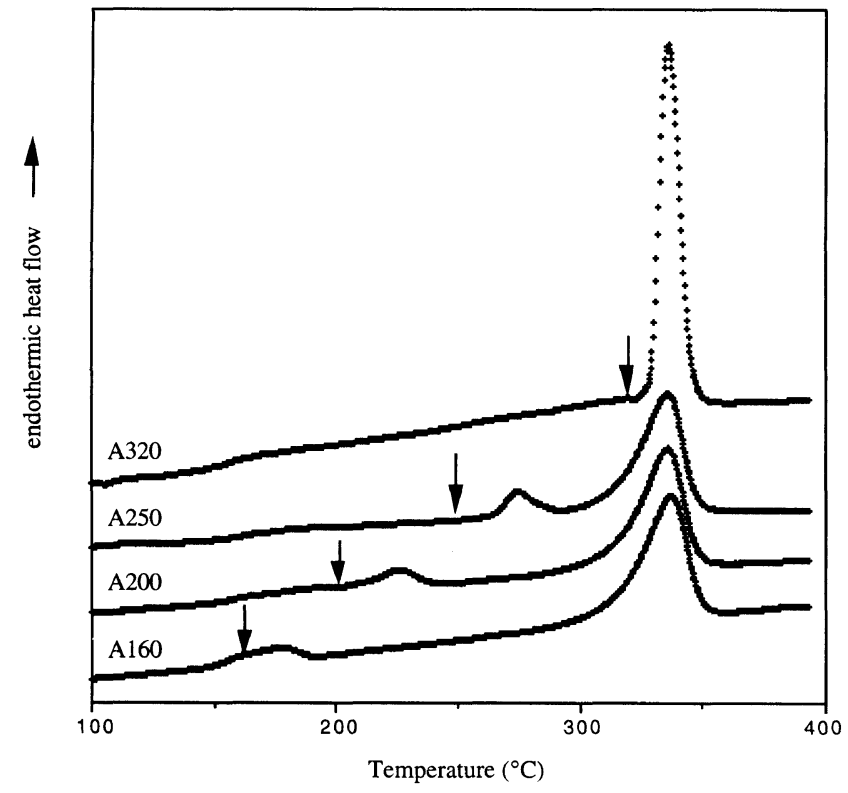

Figure 1. DSC traces recorded at $100^{\circ} \mathrm{C} \cdot \mathrm{min}^{-1}$ for the semicrystalline PEEK samples.

Table II. Glass transition characterization of PEEK samples

\begin{tabular}{cccc}
\hline Sample name & Glass temperature & $\Delta C_{\mathrm{p}} / \mathrm{Jg}^{-1} \mathrm{~K}^{-1 \mathrm{a}}$ & $X_{\mathrm{arm}}$ \\
\hline A & $147 \pm 1$ & $0.250 \pm 0.005$ & $0 \pm 0.02$ \\
A160 & $-\underbrace{\mathrm{b}}_{\mathrm{b}}$ & $0.13 \pm 0.01$ & $0.38 \pm 0.02$ \\
A200 & $162 \pm 1$ & $0.13 \pm 0.01$ & $0.34 \pm 0.02$ \\
A250 & $163 \pm 1$ & $0.15 \pm 0.01$ & $0.27 \pm 0.02$ \\
A320 & $150 \pm 1$ & &
\end{tabular}

${ }^{\mathrm{a}} \Delta C_{\mathrm{p}}$ is determined per gram of amorphous phase. ${ }^{\mathrm{b}}$ Determination is not possible because the lower endotherm is located just after the specific jump.

samples can be assumed to be a three-phase materials consisting of lamellar crystals, amorphous phase, and an interphase region so-called the rigid amorphous phase. The rigid amorphous fraction, $X_{\text {arm }}$, can be defined by:

$$
X_{\mathrm{arm}}=1-\frac{\Delta C_{\mathrm{p}}^{\mathrm{sc}}}{\Delta C_{\mathrm{p}}^{\mathrm{a}}}-X_{\mathrm{cm}}
$$

where $X_{\mathrm{cm}}$ is the weight crystallinity index, $\Delta C_{\mathrm{p}}^{\mathrm{a}}$ is the specific heat jump at $T_{\mathrm{g}}$ of a $100 \%$ amorphous sample and $\Delta C_{\mathrm{p}}^{\mathrm{sc}}$ is the specific heat jump of the semicrystalline sample.

Table II shows that the rigid amorphous fraction tends to decrease with the annealing temperature. Moreover, A200 and A250 samples exhibit a higher glass transition temperature and a higher rigid amorphous fraction than the A320 sample. It indicates that the cross-linking degree of amorphous phase induced by crystalline phase is enhanced for the A200 and A250 samples exhibited a lower degree of crystallinity than the A320 one. Then, the crystallinity index seems not to be the one parameter which control the molecular mobility in the amorphous phase. The high $T_{\mathrm{g}}$ and $X_{\mathrm{arm}}$, especially for the A200 sample, could be explained by its double melting behavior related to the double crystallite population, i.e., the distribution of crystalline entities within the amorphous phase. $^{24}$ Then, the magnitude of interactions between phases can be evaluated through such parameters. 


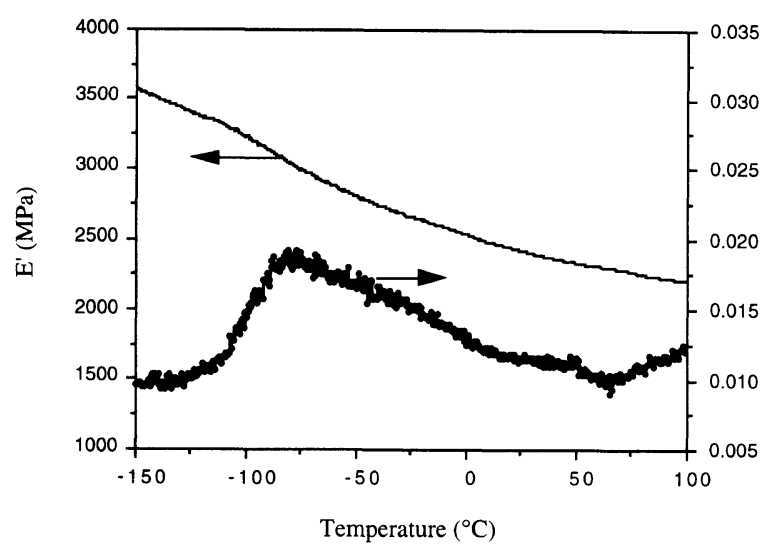

Figure 2. Storage modulus $\left(E^{\prime}\right)$ and loss tangent $(\tan \delta)$ of dry amorphous PEEK in the $\beta$-relaxation range (1 Hz).

\section{Subglass Relaxations: Experimental Data}

The evolution of $\tan \delta$ and $E^{\prime}$ at $1 \mathrm{~Hz}$ of dry amorphous PEEK with temperature is shown in Figure 2. A broad mechanical spectrum can be observed over a large temperature range, i.e., from $-100^{\circ} \mathrm{C}$ to $+70^{\circ} \mathrm{C}$. According to previous studies, ${ }^{13,15}$ this relaxation can be separated into two processes. At temperatures below $-50^{\circ} \mathrm{C}(1 \mathrm{~Hz})$, the $\beta_{1}$ process obeys an Arrhenius law. The motions giving rise to this $\beta_{1}$ transition seems to be non-cooperative with an activation energy close to $50 \mathrm{k} \mathrm{J} \mathrm{mol}^{-1}$. At higher temperature, the $\beta_{2}$ process displays a positive activation entropy close to $164 \mathrm{~J} \mathrm{~mol}^{-1}$ $\mathrm{K}^{-1}$. This value of the $\beta_{2}$ activation entropy seems to be high compared to values determined for subglass relaxations in other polymers $\left(48 \mathrm{~J} \mathrm{~mol}^{-1} \mathrm{~K}^{-1}\right.$ for PMMA $^{25}$; $44 \mathrm{~J} \mathrm{~mol}^{-1} \mathrm{~K}^{-1}$ for polypropylene ${ }^{26}$ ) and close to the value found for the main relaxation of $\mathrm{PMMA}^{27}\left(168 \mathrm{~J} \mathrm{~mol}^{-1} \mathrm{~K}^{-1}\right)$. Consequently, the motions at the origin of the $\beta_{2}$ process could arise from cooperative molecular motions.

The $\tan \delta$ spectra of the semicrystalline samples are shown in Figure 3. The comparison between the spectra of semicrystalline and amorphous PEEK in the $\beta_{1}$ region shows that the presence of a crystalline phase leads to the following changes (Table III):

(i) a decrease in the $\tan \delta$ level with increasing the degree of crystallinity;

(ii) a decrease in the strength of the $\beta_{1}$ relaxation;

(iii) no significant change in the activation energy, $E_{\mathrm{a}}$, and preexponential factor, $f_{0}$, determined from the Arrhenius equation for the $\beta_{1}$ transition.

In the $\beta_{2}$ temperature range, the crystalline phase induces not only a decrease in the $\tan \delta$ level but also a change in the pattern of the relaxation, well detected for the A200 and A250 samples.

\section{Subglass Relaxations: Mechanical Modelling of the \\ Viscoelastic Behavior}

To predict the reinforcement effect induced by crystalline phase and then to give evidence for interactions between phases, viscoelastic behavior of semicrystalline PEEK films can be performed through a mechanical modelling. Models as Takayanagi, ${ }^{28,29}$ HalpinTsaï and Halpin-Kardos ${ }^{30-34}$ based on a lack of connection between mechanical behavior of the two phases, have been considered in the literature to predict the
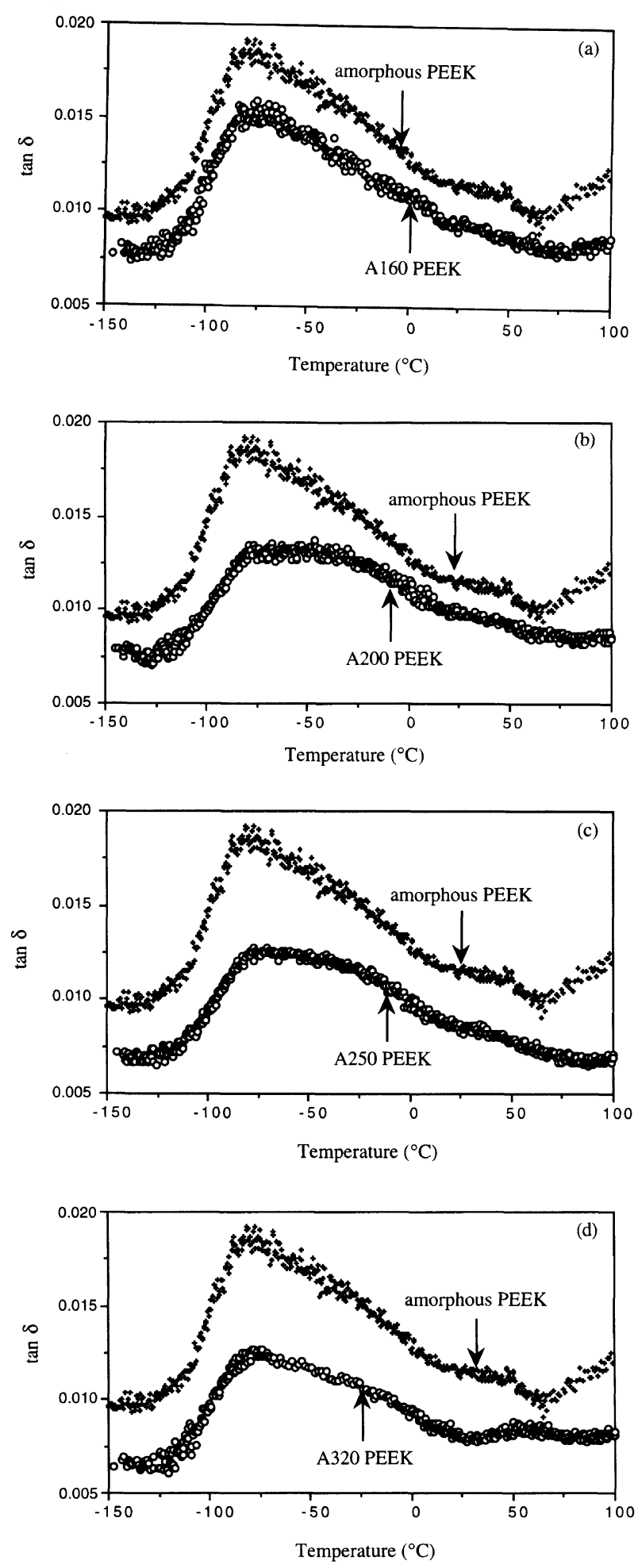

Figure 3. Isochronal spectra $(1 \mathrm{~Hz})$ of the PEEK samples: A160 (a); A200 (b); A250 (c); A 320 (d). $\tan \delta$ spectrum of dry amorphous PEEK sample is superimposed.

Table III. Characteristic parameters of the $\beta_{1}$ relaxation

\begin{tabular}{ccccr}
\hline $\begin{array}{c}\text { Sample } \\
\text { name }\end{array}$ & $\begin{array}{c}T_{\max } /{ }^{\circ} \mathrm{C} \\
\text { at } 1 \mathrm{~Hz}\end{array}$ & $E_{\mathrm{a}} / \mathrm{k} \mathrm{J} \mathrm{mol}^{-1}$ & $f_{0} / \mathrm{Hz}$ & $\begin{array}{r}\tan \delta \cdot 10^{+3} \\
\text { at }-140^{\circ} \mathrm{C}\end{array}$ \\
\hline A & $\mathbf{- 7 9} \pm 2$ & $\mathbf{5 0} \pm \mathbf{5}$ & $\mathbf{1 0}^{15 \pm 1}$ & $\mathbf{1 0 . 0 \pm 0 . 1}$ \\
$\mathrm{A} 160$ & $-79 \pm 2$ & $55 \pm 5$ & $10^{14 \pm 1}$ & $8.0 \pm 0.1$ \\
$\mathrm{~A} 200$ & $-77 \pm 2$ & $55 \pm 5$ & $10^{16 \pm 1}$ & $7.5 \pm 0.1$ \\
A250 & $-77 \pm 2$ & $50 \pm 5$ & $10^{15 \pm 1}$ & $7.0 \pm 0.1$ \\
A320 & $-77 \pm 2$ & $50 \pm 5$ & $10^{12 \pm 1}$ & $6.5 \pm 0.1$ \\
\hline
\end{tabular}


semicrystalline viscoelastic behavior in the glass transition temperature range. Among these modellings, we have chosen the Halpin-Kardos approach for which the semicrystalline polymer is assumed to be a quasiisotropic laminate constituted by stacking up planes. Each plane contains unidirectionally oriented lamellae. The mechanical characteristics of each plies $\left(E_{11}^{*}, E_{22}^{*}\right.$, $G_{12}^{*}$ ) are defined by the Halpin-Tsaï relations (eq 2 ). In these equations, the crystalline entities geometry and their anisotropic character are taking into account through $\xi_{\mathrm{ij}}$ parameters and different moduli $\left(E_{\mathrm{iic}}\right.$ and $\left.G_{\mathrm{ijc}}\right)$, respectively.

* Halpin-Tsaï equations:

$$
\begin{gathered}
\frac{E_{11}^{*}}{E_{\mathrm{m}}^{*}}=\frac{1+\xi_{11} \eta_{11} X_{\mathrm{c}}}{1-\eta_{11} X_{\mathrm{c}}} \text { with } \eta_{11}=\frac{\frac{E_{11 \mathrm{c}}}{E_{\mathrm{m}}^{*}}-1}{\frac{E_{11 \mathrm{c}}}{E_{\mathrm{m}}^{*}+\xi_{11}}} \\
\text { and } \xi_{11}=2 \cdot \frac{L}{e} \\
\frac{E_{22}^{*}}{E_{\mathrm{m}}^{*}}=\frac{1+\xi_{22} \eta_{22} X_{\mathrm{c}}}{1-\eta_{22} X_{\mathrm{c}}} \text { with } \eta_{22}=\frac{\frac{E_{22 \mathrm{c}}}{E_{\mathrm{m}}^{*}}-1}{\frac{E_{22 \mathrm{c}}}{E_{\mathrm{m}}^{*}+\xi_{22}}} \\
\frac{G_{12}^{*}}{G_{\mathrm{m}}^{*}}=\frac{1+\xi_{12} \eta_{12} X_{\mathrm{c}}}{1-\eta_{12} X_{\mathrm{c}}} \quad \text { with } \eta_{12}=\frac{\frac{l}{e}}{\frac{G_{\mathrm{m}}}{G_{12 \mathrm{c}}}} \\
\text { and } \xi_{12}^{*}=\left(\frac{l}{e}\right)^{\sqrt{3}}
\end{gathered}
$$

where $E_{11 \mathrm{c}}$ and $E_{22 \mathrm{c}}$ are the elastic moduli of crystalline phase in the directions 1 and 2; $G_{12 \mathrm{c}}$ is the in-plane elastic shear modulus of crystalline phase; $E_{11}^{*}$ and $E_{22}^{*}$ are the complex moduli of semicrystalline polymer, respectively, in the 1 and 2 direction; $G_{12}^{*}$ is the complex shear modulus of crystalline phase in the $(1,2)$ plane; $L, l$, and $e$, are respectively the length, the width and the thickness of the crystalline lamella; $X_{\mathrm{c}}$ is the volume crystallinity index of the polymer; $E_{\mathrm{m}}^{*}$ and $G_{\mathrm{m}}^{*}$ are, respectively, the complex tensile and shear moduli of the amorphous phase.

The semicrystalline polymer is built by stacking these plies with their principal axes at $0^{\circ}, \pm 45^{\circ}, 90^{\circ}$ to the principal in plane axis of the sheet. Then, the complex modulus of the composite materials, $G^{*}$, can be evaluated through the following equation:

$$
\begin{aligned}
G^{*}= & \frac{1}{8 \cdot\left(1-v_{12} \cdot v_{21}\right)} E_{11}^{*}+\frac{1-2 v_{12}}{8 \cdot\left(1-v_{12} \cdot v_{21}\right)} E_{22}^{*} \\
& +\frac{1}{2} G_{12}^{*}
\end{aligned}
$$

where $v_{12}$ and $v_{21}$ are the Poisson's ratios of the semicrystalline polymer. For calculation, $v_{12}$ and $v_{21}$ are assumed to be real. They are determined by the rule of
Table IV. Morphological parameters taken into account of the Halpin-Kardos modeling of the $\beta$ relaxation

\begin{tabular}{lll}
\hline Length & $L=2500 \AA$ & According to SEM observations \\
Width & $l=L / 10=250 \AA$ & $\begin{array}{l}\text { According to Jourdan } \\
\text { Ao }\end{array}$ \\
Thickness & $e=60 \AA$ & According to SAXS analysis
\end{tabular}

Poisson's ratio $v_{12}=v_{21}=X_{\mathrm{cv}} \cdot v_{\mathrm{c}}+\left(1-X_{\mathrm{cv}}\right) \cdot v_{\mathrm{m}}$ where $v_{\mathrm{c}}$ and $v_{\mathrm{m}}$ are respectively the Possion's ratio of crystalline and amorphous phases

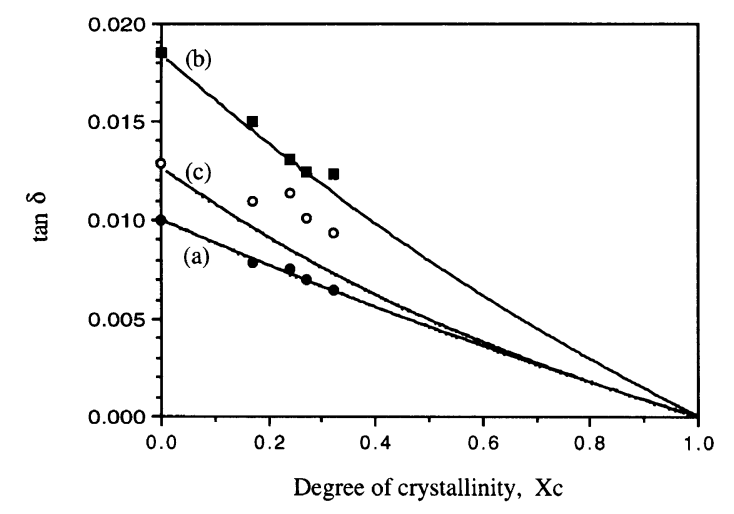

Figure 4. Evolution of experimental $\tan \delta$ versus the crystallinity ratio at $-130^{\circ} \mathrm{C}(\bigcirc)$, at $-80^{\circ} \mathrm{C}(\square)$ and at $-0^{\circ} \mathrm{C}(\bigcirc)$. Continuous lines indicate the theoretical evolution issue from the Halpin-Kardos modelling at $-130^{\circ} \mathrm{C}(\mathrm{a})$, at $-80^{\circ} \mathrm{C}(\mathrm{b})$, and $0^{\circ} \mathrm{C}(\mathrm{c})$.

mixtures (Table IV).

The morphological parameters considered for the mechanical modelling are reported in Table IV. Moduli of crystaline phase have been determined by Nishino et $a l .{ }^{35}$ by WAXS analysis. The complex modulus of the amorphous phase is determined by the experimental analysis of the amorphous sample.

\section{Subglass Relaxations: Simulated Data for Semicrystalline Samples}

Figure 4 shows the evolution of the precicted and measured $\tan \delta$ dependence $v s$. the degree of crystallinity at the following temperatures, $-130^{\circ} \mathrm{C}$, i.e., at temperature lower than the beta relaxations, $-80^{\circ} \mathrm{C}$, i.e., the $\beta_{1} \tan \delta$ maximum and $0^{\circ} \mathrm{C}$, i.e., in the $\beta_{2}$ temperature range.

The theoretical $\tan \delta$ level decreases with increasing the degree of crystallinity. At $-130^{\circ} \mathrm{C}$ and at $-80^{\circ} \mathrm{C}$, predicted $\tan \delta$ values are in good agreement with experimental points whatever the degree of crystallinity can be. Then, it can be concluded that the modifications of the $\beta_{1}$ spectrum induced by the crystalline phase only result from the reinforcement effect of the amorphous phase. Accordingly, crystalline entities do not modify the nature of the motions at the origin of the $\beta_{1}$ relaxation. This result is consistent with previous conclusion, i.e., the $\beta_{1}$ component originates from localized and non cooperative motions in the amorphous phase. ${ }^{13,15}$

In contrast, in the $\beta_{2}$ temperature range and in particular at $0^{\circ} \mathrm{C}$, mechanical modelling tends to underestimate the $\tan \delta$ values. Then, it can be concluded that changes in the $\beta_{2}$ relaxation do not only result from mechanical coupling effects. The crystalline phase could also induce changes in the molecular mobility of structural units involved in the $\beta_{2}$ transition. Such 

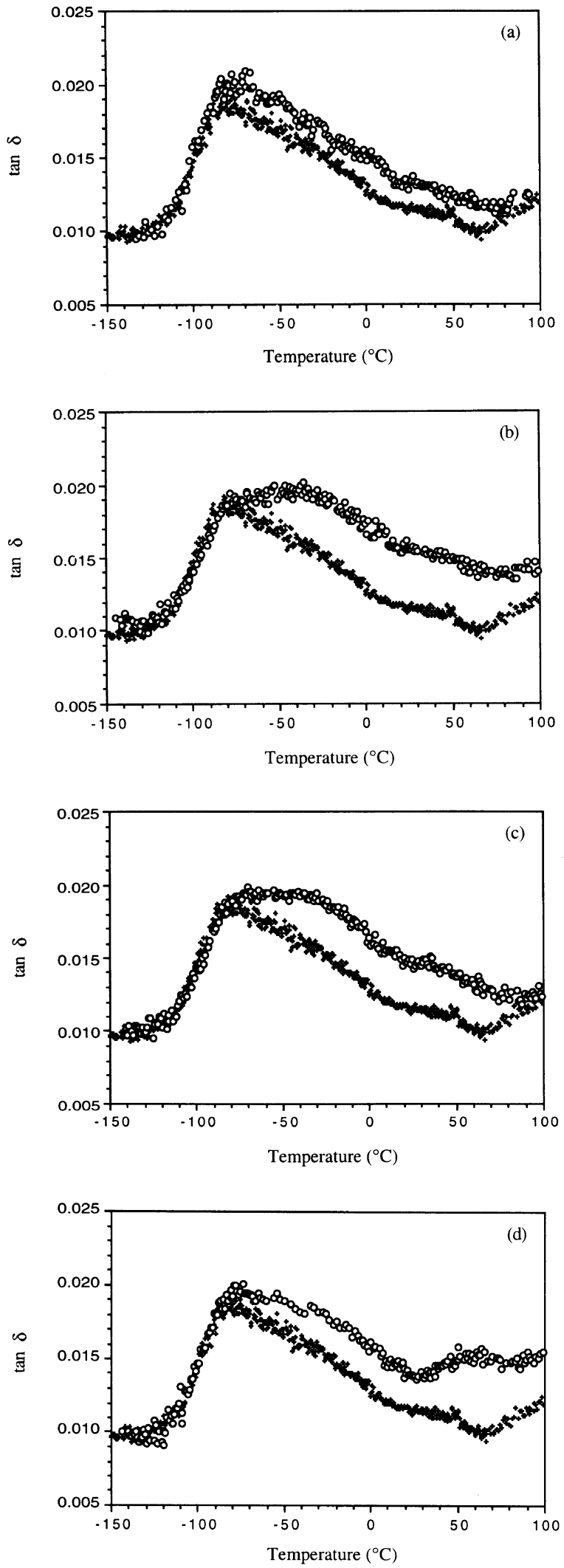

Figure 5. $\tan \delta$ spectrum $(1 \mathrm{~Hz})$ versus temperature for the amorphous PEEK sample $(+)$ and the separated amorphous phase $(O)$ of semicrystalline samples: A160 (a); A200 (b); A250 (c); A320 (d).

modifications could concern the macromolecular conformations in the vicinity of crystalline entities and/or the magnitude of intermolecular interactions.

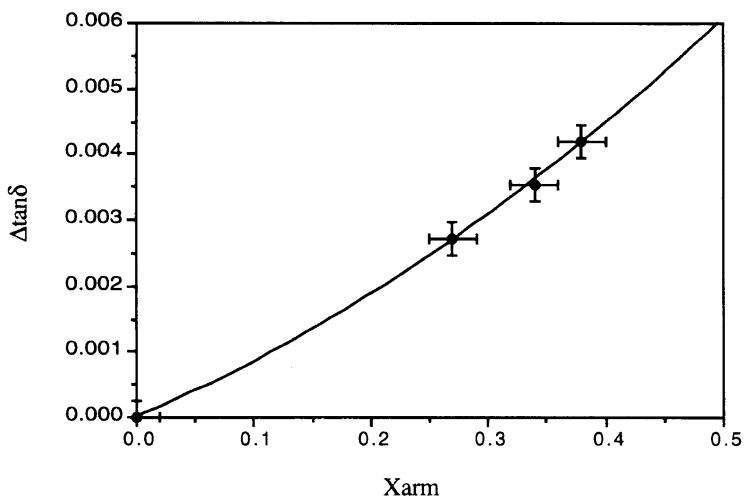

Figure 6. Evolution of the $\Delta \tan \delta$ at $0^{\circ} \mathrm{C}$ versus the rigid amorphous fraction, $X_{\text {arm }}$.

Subglass Relaxations: Separation of the Dynamic Mechanical Behavior between Phases

To keep only the changes in the molecular mobility of chains induced by the crystalline entities, it is valuable to remove the reinforcement effect through the mechanical modelling discussed above.

Then, the complex Young's modulus of the amorphous phase of the semicrystalline polymer can be assessed through the inversion of eq 3 . The complex equation of the fourth degree of the complex modulus is divided in a system of two real equations. This system is converted into a first equation which only depends on the real part of the amorphous complex modulus and in a second expression which depends on the real and the imaginary parts of the modulus. ${ }^{36}$

Figure 5 shows the dynamic mechanical behavior $v s$. temperature of the so-separated amorphous phase of the semicrystalline sample. For comparison, experimental data of the amorphous PEEK are superimposed.

Whatever the annealing temperature, $\tan \delta$ spectrum of the so-separated amorphous phase in the $\beta_{1}$ region is well-superimposed to that of displayed by the amorphous PEEK sample (A). At temperatures higher than $-80^{\circ} \mathrm{C}$, $\tan \delta$ values of the so-separated amorphous phase are higher than that of displayed by the amorphous sample (A). In the $\beta_{2}$ region, difference in $\tan \delta$ level-noted $\Delta \tan \delta$ - between predicted and experimental data display a maximum between $-25^{\circ} \mathrm{C}$ and $+25^{\circ} \mathrm{C}$ (Fig. 5). This $\Delta \tan \delta$ maximum increases with the fraction of rigid amorphous phase (Fig. 6) and the glass transition temperature. This evolution confirms that the changes in the pattern of the $\beta_{2}$ transition induced by the crystalline phase result from modifications of the molecular mobility of chain in the vicinity of crystalline entities. This conclusion is consistent with the results of Starkweather analysis ${ }^{13-15}$ and could confirm that the molecular motions at the origin of the $\beta_{2}$ relaxation could be of a cooperative kind.

\section{CONCLUSIONS}

The influence of a crystalline phase on the beta relaxation has been investigated for PEEK films. The conclusions issued from Halpin-Kardos modelling are the followings:

(i) The decrease in both the $\tan \delta$ level at temperatures lower than the $\beta$ relaxation and the strength of 
the $\beta_{1}$ relaxation exhibited by the semicrystalline samples with respect to the amorphous one only results from the mechanical coupling between phases.

(ii) The changes in the pattern observed in the $\beta_{2}$ region accompanied by a decrease in the $\tan \delta$ level in this temperature range originate from both mechanical coupling and modifications of the molecular mobility of macromolecular chains located near crystalline entities, i.e., the rigid amorphous phase.

Acknowledgments. The authors are grateful to $\mathrm{Mr}$. K. D. Gilliatt and Mrs. A. Guinet (ICI film UK \& France) for providing amorphous PEEK films. They are indebted Mr. S. Dassin and Dr. M. Fugier for helping in the Halpin-Kardos modelling.

\section{REFERENCES}

1. D. J. Kemmish and J. N. Hay, Polymer, 26, 905 (1985).

2. P. Cebe, S. Y. Chung, and S.-D. Hong, J. Appl. Polym. Sci., 33, 487 (1987).

3. J.-N. Chu and J. M. Schultz, J. Mater. Sci., 24, 4538 (1989).

4. J. A. Schroeder, P. A. Madsen, and R. T. Foister, Polymer, 28, 929 (1987).

5. L. Monnerie, Makromol. Chem., Macromol. Symp., 48/49, 125 (1991).

6. J.-M. Muracciole and Y. A. Bertin, J. Phys. III, 1, 1881 (1991).

7. S. J. Wu, J. Appl. Polym. Sci., 46, 619 (1992).

8. M. B. M. Mangion, J. Y. Cavaille, and J. Perez, Phil. Mag. A, 66, 773 (1992).

9. C. Xiao, J. Y. Jho, and A. F. Yee, Macromolecules, 27, 2761 (1994).

10. K. Ahlborn, Cryogenics, 28, 234 (1988).

11. A. Jonas and R. Legras, Macromolecules, 26, 813 (1993)

12. T. Sasuga and M. Hagiwara, Polymer, 26, 501 (1985).
13. L. David and S. Etienne, Macromolecules, 25, 4302 (1992).

14. R. K. Krishnaswamy and D. S. Kalika, Polymer, 35, 1157 (1994).

15. C. Bas and N. D. Albérola, Polym. Eng. Sci., 36, 244 (1996).

16. N. Albérola, C. Bas, and P. Mélé, C. R. Acad. Sci. Paris II, 319, 1129 (1994).

17. N. Albérola and A. Bergeret, Polym. Composites, 15, 442 (1994).

18. D. J. Blundell and B. N. Osborn, Polymer, 24, 953 (1983).

19. A. Jonas, Ph.D. Thesis, Université Catholique de Louvain (1992), 219 p.

20. Y. Lee, R. S. Porter, and J. S. Lin, Macromolecules, 22, 1756 (1989).

21. G. S. H. Gupta and R. Salovey, Polym. Eng. Sci., 30, 453 (1990).

22. S. Z. D. Cheng, M.-Y. Cao, and B. Wunderlinch, Macromolecules, 19, 1868 (1986).

23. P. Huo and P. Cebe, Macromolecules, 25, 902 (1992).

24. C. Bas, P. Battesti, and N. D. Albérola, J. Appl. Polym. Sci., 53, 1745 (1994)

25. E. Muzeau, J. Perez, and G. P. Johari, Macromolecules, 24, 4713 (1991).

26. H. W. Starkweather, Jr., P. Avakian, R. R. Matheson, Jr., J. J. Fontanella, and M. C. Wintersgill, Macromolecules, 25, 6871 (1992).

27. H. W. Starkweather, Jr., Macromolecules, 23, 328 (1990).

28. M. Takayanagi, K. Imada, and T. Kajiyama, J. Polym. Sci. C, 15, 263 (1966).

29. M. Takayanagi, Proceedings 4th International Congress on Rheology, Part 1, E. H. Lee and A. L. Copley, Ed., Interscience, New York, N.Y., 1965, p 161.

30. C. Jourdan, Ph.D. Thesis, Institut National des Sciences Appliquées de Lyon (1987), 185 p.

31. N. Albérola, J.-Y. Cavaillé, and J. Pérez, Eur. Polym. J., 28, 949 (1992).

32. J. C. Halpin and J. L. Kardos, Polym. Eng. Sci., 16, 344 (1976).

33. J. C. Halpin and J. L. Kardos, J. Appl. Phys., 43, 2235 (1972).

34. J. L. Kardos, J. Raisoni, S. Piccarolo, and J. C. Halpin, Polym. Eng. Sci., 19, 1000 (1979).

35. T. Nishino, K. Tada, and K. Nakamae, Polymer, 33, 736 (1992).

36. C. Bas, Ph.D. Thesis, Université de Savoie (1994), 252 p. 